\title{
A COMPARISON OF VENTRAL TEGMENTAL NEURONS PROJECTING TO OPTIC FLOW REGIONS OF THE INFERIOR OLIVE VS. THE HIPPOCAMPAL FORMATION
}

\author{
I. R. WINSHIP, ${ }^{\text {a }}$ J. M. P. PAKAN, ${ }^{b}$ K. G. TODD ${ }^{b, c}$ \\ AND D. R. WONG-WYLIE ${ }^{a, b *}$ \\ ${ }^{a}$ Department of Psychology, University of Alberta, Edmonton, Alberta, \\ Canada T6G 2E9 \\ ${ }^{b}$ Centre for Neuroscience, University of Alberta, Edmonton, Alberta, \\ Canada \\ ${ }^{c}$ Department of Psychiatry, University of Alberta, Edmonton, Alberta, \\ Canada
}

\begin{abstract}
The ventral tegmental area (catecholaminergic group $\mathrm{A10}$ ) is a midbrain region characterized by concentrated dopaminergic immunoreactivity. Previous studies in pigeons show that the ventral tegmental area provides a robust projection to the hippocampal formation and to the medial column of the inferior olive. However, the distribution, morphology, and neurochemical content of the neurons that constitute these projections have not been resolved. In this study, we used a combination of retrograde tracing techniques and immunofluorohistochemistry to address these issues. Retrograde tracers were used to demonstrate that the distribution of ventral tegmental area neurons projecting to the hippocampus and the inferior olive overlap in the caudoventral ventral tegmental area. The hippocampus- and inferior olive-projecting ventral tegmental area neurons could not be distinguished based on morphology: most neurons had small- to medium-sized multipolar or fusiform soma. Doublelabeling with fluorescent retrograde tracers revealed that the hippocampus- and medial column of the inferior olive-projecting neurons were found intermingled in the ventral tegmental area, but no cells were double labeled; i.e. individual ventral tegmental area neurons do not project to both the hippocampal formation and medial column of the inferior olive. Finally, we found that a minority $(8.2 \%)$ of ventral tegmental area neurons providing input to the hippocampus were tyrosine hydroxylase-immunoreactive, whereas none of the inferior olive-projecting neurons were tyrosine hydroxylase positive. Combined, our findings show that the projections to the hippocampus and olivocerebellar pathway arise from intermixed subpopulations of ventral tegmental area neurons with indistinguishable morphology but only the hippocampal projection involves dopaminergic neurons. We suggest that equivalent projections from the ventral tegmental area to the hippocampal formation and inferior olive exist
\end{abstract}

${ }^{*}$ Correspondence to: D. R. Wong-Wylie, Department of Psychology, University of Alberta, Edmonton, Alberta, Canada T6G 2E9. Tel: +1-780492-5274; fax: +1-780-492-1768.

E-mail address: dwylie@ualberta.ca (D. R. Wong-Wylie).

Abbreviations: AOS, accessory optic system; BDA, biotinylated dextran amine; CTB, cholera toxin subunit B; FITC, fluorescein isothiocyanate; LM, lentiformis mesencephali; mclO, medial column of the inferior olive; $\mathrm{nBOR}$, nucleus of the basal optic root; $\mathrm{nBORd}$, nucleus of the basal optic root, pars dorsalis; nBORp, nucleus of the basal optic root, proper; NHS, normal horse serum; PB, phosphate buffer; PBS, phosphate-buffered saline; TH, tyrosine hydroxylase; VTA, ventral tegmental area; VTRZ, visual tegmental relay zone. in mammals and discuss their potential role in the processing of optic flow and the analysis of self-motion. () 2006 IBRO. Published by Elsevier Ltd. All rights reserved.

Key words: dopamine, path integration, navigation, tyrosine hydroxylase, accessory optic system, optic flow.

Ventral tegmental area (VTA; catecholaminergic group $\mathrm{A} 10)$ is a midbrain region characterized by dense dopaminergic immunoreactivity (Lindvall and Björklund, 1983; for review see Oades and Halliday, 1987; Gasbarri et al., 1997). In birds, the VTA, (formerly known as the area ventralis of Tsai (Reiner et al., 2004)), resides medial to the nucleus of the basal optic root (nBOR) and lateral to the third cranial nerve (Fuxe and Ljunggren, 1965; Ikeda and Gotoh, 1971; Dube and Parent, 1981; Kiss and Péczely, 1987; Bailhache and Balthazart, 1993; Moons et al., 1994; Wynne and Güntürkün, 1995; Durstewitz et al., 1999). The VTA gives rise to a robust dopaminergic input throughout the telencephalon that has been implicated in various behaviors including cognition, reward, motivation, and motor function (for review, see Horel, 1988; Oades and Halliday, 1987; Gasbarri et al., 1997; Wise 2004).

In the present study, we characterized two efferent pathways of the VTA (illustrated in Fig. 1) that have been implicated in behaviors requiring the analysis of the distinct visual patterns produced during self-motion (termed "optic flow"; Gibson 1954). In birds, optic flow processing begins with two retinal recipient nuclei, the nBOR of the accessory optic system (AOS) and the pretectal nucleus lentiformis mesencephali (LM; Karten et al., 1977; Reiner et al., 1979; Fite et al., 1981; Gamlin and Cohen, 1988a). LM and $\mathrm{nBOR}$ project to the medial column of the inferior olive (mclO) directly and indirectly via a relay zone in the VTA (Brecha et al., 1980; Gamlin and Cohen, 1988b). mclO in turn provides climbing fiber input to the vestibulocerebellum (Clarke, 1977; Arends and Voogd, 1989). This pathway, and the mammalian equivalent, is important for the analysis of self-motion and the generation of the "optokinetic response" for gaze stabilization (for reviews see Simpson, 1984; Waespe and Henn, 1987; Simpson et al., 1988b).

The second pathway illustrated in Fig. 1 is a projection from the VTA to the hippocampal formation (Casini et al., 1986; Atoji and Wild, 2004). Some VTA neurons projecting to the hippocampus appear to receive efferents from LM and $\mathrm{nBOR}$ and respond to optic flow fields produced by self-rotation or self-translation (Wylie et al., 1999a). As such, Wylie et al. (1999a) suggested that this projection 


\section{"optokinetic response"}

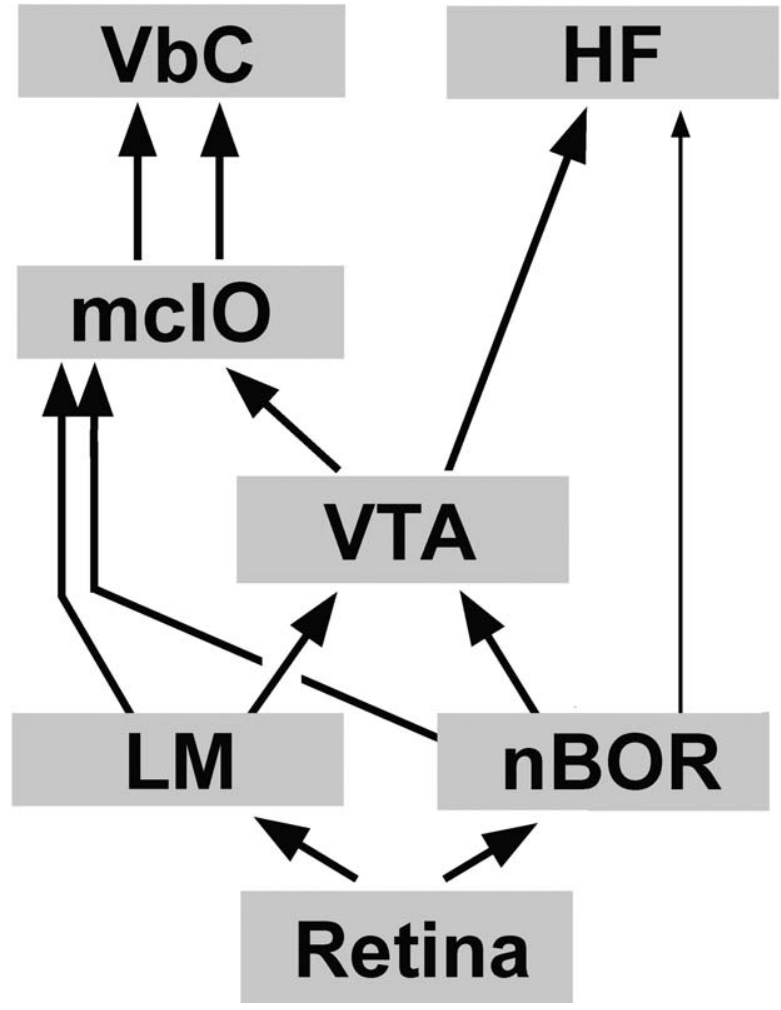

Fig. 1. Schematic illustrating the interconnections of the AOS, pretectum, olivocerebellar pathway, and the hippocampal formation (HF). Visual information from self-motion arrives in the nBOR of the AOS and the nucleus LM of the pretectum directly from the retina. Optic flow information arrives at the mclO directly from $\mathrm{LM}$ and $\mathrm{nBOR}$ and indirectly via the VTA. mclO provides climbing fiber input essential for the optokinetic response to the vestibulocerebellum $(\mathrm{VbC})$. Optic flow information may reach the hippocampus via a robust projection from the VTA and/or a small projection directly from the nBOR: this information may be used for path integration.

might be important for conveying optic flow information for "path integration," a form of spatial navigation based on ideothetic cues from self-motion (a.k.a. "dead-reckoning"; Darwin, 1873). Studies in rats showed that the hippocampus is critical for path integration (Foster et al., 1989; Wilson and McNaughton, 1993; McNaughton et al., 1995, 1996; Whishaw et al., 1997; Whishaw and Maaswinkel, 1998).

The aim of the present study was to determine if projections from the VTA to the $\mathrm{mclO}$ and hippocampus arise from different populations of neurons. There are several questions in this regard. First, because the VTA is a reticular area with indistinct borders in Nissl-stained tissue, it was not clear that the $\mathrm{mclO}$ projecting neurons reside within VTA as defined by dopaminergic immunohistochemical studies. Thus, in this study we examined the extent of tyrosine hydroxylase (TH)-immunoreactive regions of the ventral tegmentum in order to define the borders of the VTA in pigeons. Second, because it was not known if the regions of the VTA that project to the hippocampus and $\mathrm{mclO}$ are exclusive or overlapping, or if individual neurons project to both the hip- pocampus and $\mathrm{mclO}$, we assessed the distribution and morphology of hippocampus- and mclO-projecting VTA neurons using conventional and fluorescent retrograde tracers. Finally, because it is not known if the mclO- or hippocampusprojecting VTA neurons are dopaminergic, we combined fluorescent retrograde tracing with immunofluorohistochemistry to determine the extent to which catecholaminergic neurons are involved in these two projections.

\section{EXPERIMENTAL PROCEDURES}

\section{Surgery and extracellular recording}

The methods reported herein conform to national and international guidelines on the ethical use of animals as defined by the Canadian Council on Animal Care and were approved by the Biosciences Animal Care and Policy Committee at the University of Alberta. Concerted efforts were made to minimize animal suffering and the number of animals used in this study. Twenty-five Silver King and homing pigeons, from a local supplier, were anesthetized with a ketamine $(65 \mathrm{mg} / \mathrm{kg}$; Animal Health Inc., Cambridge, ON, Canada)-xylazine (8 mg/kg; Bayer, Toronto, ON, Canada) cocktail (i.m.). Depth of anesthesia was monitored via toe pinch and supplemental doses were administered as necessary. The animals were placed in a stereotaxic device with pigeon ear bars and beak adapter so that the orientation of the skull conformed to the atlas of Karten and Hodos (1967). Access to the mclO or hippocampus was achieved by removing bone and dura over the cerebellum or the caudo-medial hippocampus, respectively. In the case of hippocampal injections, the injections were based on stereotaxic coordinates targeting the caudal dorsomedial (Atoji and Wild, 2004) hippocampal formation. For mclO injections, single-unit extracellular recordings were used to confirm the injection site. To record the activity of optic flow units in the $\mathrm{mclO}$, glass micropipettes filled with $2 \mathrm{M} \mathrm{NaCl}$ and having tip diameters of 4-5 $\mu \mathrm{m}$ were advanced through the cerebellum and into the brainstem using a hydraulic microdrive (Frederick Haer \& Co.). Extracellular signals were amplified, filtered, and fed to a window discriminator and data analysis system (Cambridge Electronic Designs; 1401plus).

Inferior olivary units are easily identified based on their characteristically low firing rate (approximately 1 spike/s) and proximity to the base of the brain. Upon isolation of a unit in the inferior olive, the optic flow preference of the unit was qualitatively determined. In most cases, moving a large $\left(90 \times 90^{\circ}\right)$ handheld visual stimulus, consisting of black bars, squiggles, and dots on a white background, in the receptive field of the unit was sufficient to determine the direction-selectivity. In some cases, a computer-generated stimulus (see Winship and Wylie, 2001) was used to confirm the preferred direction. After identification of an optic flow neuron in the $\mathrm{mclO}$, the recording electrode was replaced with a glass micropipette (tip diameter, 10-20 $\mu \mathrm{m}$ ) containing a retrograde tracer.

\section{Cholera toxin subunit B (CTB)/biotinylated dextran amine (BDA) injections and visualization}

In 12 birds (hippocampal injections, $n=5$; mclO injections, $n=7$ ), low-salt CTB (Sigma, St. Louis, MO, USA; $1 \%$ in $0.1 \mathrm{M}$ phosphatebuffered saline [PBS, pH 7.4]) was iontophoretically injected unilaterally for 5-30 min ( $+4 \mu \mathrm{A}, 7 \mathrm{~s}$ ON, $7 \mathrm{~s}$ OFF). In one case, BDA (Molecular Probes, Eugene, OR, USA; molecular weight $=3000$; $10 \%$ in $0.1 \mathrm{M}$ phosphate buffer [PB; $\mathrm{pH}=7.4]$ ) was iontophoretically injected $(+3 \mu \mathrm{A}, 1 \mathrm{~s} \mathrm{ON}, 1 \mathrm{~s}$ OFF) into the mclO for $5 \mathrm{~min}$. For the cases involving iontophoresis into the $\mathrm{mclO}$, we determined the optic flow preference at the injection site prior to the injection. The electrode was left undisturbed for an additional 5 min post-injection. Post-surgery, birds were given an i.m. injection 
of buprenorphine $(0.012 \mathrm{mg} / \mathrm{kg})$ as an analgesic. After a recovery period of 3-5 days, the animals were deeply anesthetized with sodium pentobarbital $(100 \mathrm{mg} / \mathrm{kg})$ and immediately perfused with ice cold heparinized PBS $(0.9 \% \mathrm{NaCl}, 1 \mathrm{ml} / 100 \mathrm{ml}$ heparin, $0.1 \mathrm{M}$ $\mathrm{PB}$ ), followed by ice-cold paraformaldehyde (4\% in $0.1 \mathrm{M} \mathrm{PB}$; $\mathrm{pH}$ 7.4). These brains were extracted and post-fixed for $2-12 \mathrm{~h} \mathrm{(4 \%}$ paraformaldehyde, $30 \%$ sucrose in $0.1 \mathrm{M} \mathrm{PB})$ then placed in sucrose overnight ( $30 \%$ in $0.1 \mathrm{M} \mathrm{PB})$. Frozen sections, $45 \mu \mathrm{m}$ thick, were collected in the coronal plane. CTB or BDA was visualized using a cobalt chloride intensification of diaminobenzidine. These procedures have been described in detail elsewhere (BDA, Wylie et al., 1997, 1999a, 2003a,b, 2005; CTB, Lau et al., 1998; Wylie et al., 1999a,b; Crowder et al., 2000; Pakan et al., 2005; see also Wild, 1993; Veenman et al., 1992).

\section{Fluorescent tracers injections}

In five cases we used green and red fluorescent microspheres (Lumafluor Corporation, Naples, FL, USA) as retrograde tracers, which were pressure injected into the hippocampus and $\mathrm{mclO}$ using a Picospritzer II (General Valve Corp, Fairfield, NJ, USA). In two cases a single injection was made into either the $\mathrm{mclO}$ (case flIO\#1) or the hippocampus (case flHF\#1). In the other three cases (HFIO\#2, HFIO\#3, HFIO\#4) double labeling retrograde experiments were performed in which a unilateral injection of either red or green fluorescent microspheres was made in the mclO, while the alternate color was injected either ipsilaterally or bilaterally in the hippocampal formation. One other animal (case HFIO\#1) was also used for a double labeling experiment, but in this case fluorescent conjugated CTB (Molecular Probes) was injected using iontophoresis ( $+4 \mu \mathrm{A}, 7 \mathrm{~s}$ ON, $7 \mathrm{~s}$ OFF). $1 \%$ CTB-AlexaFluor 594 (red) and 488 (green) were injected into the hippocampus and ipsilateral $\mathrm{mclO}$, respectively.

After a recovery period of 2-5 days, the animals were deeply anesthetized with sodium pentobarbital and immediately perfused with ice-cold heparinized PBS. The brains were immediately extracted and then flash frozen in 2-methylbutane and stored at $-80^{\circ} \mathrm{C}$ until sectioning. Brains were embedded in optimal cutting temperature medium and $40 \mu \mathrm{m}$ coronal sections were cut through the brainstem and cerebellum with a cryostat and mounted on electrostatic slides.

\section{TH immunohistochemistry}

TH-immunoreactive neurons in the VTA were visualized in six birds. Animals were perfused with ice-cold heparinized PBS, followed by ice-cold paraformaldehyde. The brains were post-fixed for 2-12 $\mathrm{h}$ then placed in sucrose overnight. Frozen sections, $45 \mu \mathrm{m}$ thick, were collected in the coronal plane and placed into wells containing $0.1 \mathrm{M}$ PBS. The floating sections were rinsed three times with $0.1 \mathrm{M}$ PBS ( 5 min per rinse), then incubated in a solution of $0.15 \% \mathrm{H}_{2} \mathrm{O}_{2}$ in a $50 \%$ methanol solution for $15 \mathrm{~min}$ and rinsed five additional times with PBS. Sections were placed in a blocking solution containing $10 \%$ normal horse serum (NHS) $+0.4 \%$ Triton X-100 in PBS for $1 \mathrm{~h}$ at room temperature, then incubated in sheep anti-TH (1:500; Novus Biologicals) $+2.5 \% \mathrm{NHS}+0.4 \%$ Triton $\mathrm{X}-100$ in PBS for $24 \mathrm{~h}$ at $4{ }^{\circ} \mathrm{C}$. Following incubation, sections were rinsed three times with $\mathrm{PBS}$.

In two cases (TH\#1, TH\#2) a chromagen was used to visualize the TH-immunoreactivity. The sections were incubated with a solution containing the secondary antibody (biotinylated donkey anti-sheep IgG; 1:1000; Jackson Immuno) with 0.4\% Triton X-100 and $2.5 \%$ NHS in PBS for 60 min. After rinsing with PBS, avidinbiotin complex (1:100; Vector Laboratories, Burlingame, CA, USA) was added for $30 \mathrm{~min}$ at room temperature. Sections were then stained with metal-enhanced 3,3-diaminobenzadine tetrahydrochloride tablets (Sigma) for 1-5 min, dehydrated through graded ethanols, cleared with xylene, and coverslipped with Permount.
In the other four cases (HFTH\#1, HFTH\#2, IOTH\#1, IOTH\#2), tissue was incubated with a solution containing a fluorescent secondary antibody, Texas Red donkey anti-sheep lgG (1:100; Jackson Immuno), with $2.5 \%$ NHS and $0.4 \%$ Triton X-100 in PBS. Following three final rinses in PBS, the tissue was mounted on electrostatic slides. In these cases green fluorescent microspheres had been injected bilaterally into hippocampus (cases $\mathrm{HFTH \# 1}$ and HFTH\#2) or unilaterally into mclO (IOTH\#1 and IOTH\#2) 2-5 days earlier, as described above.

\section{Microscopy, image acquisition and morphological analysis}

Sections involving visualization with diaminobenzidine were viewed using standard light microscopy (Leica Laborlux) and drawings were made with the aid of a drawing tube. The sections involving fluorescent tracers or markers were examined with a compound light microscope (Leica DMRE) equipped with the appropriate fluorescence filters: Texas Red and fluorescein isothiocyanate (FITC) filters for the CTB-AlexaFluor 594 and 488 , respectively; rhodamine and FITC for the red and green latex microspheres, respectively; and Texas Red for the THimmunofluorohistochemistry. Images were acquired using a Retiga EXi FAST Cooled mono 12-bit camera (Qimaging, Burnaby $B C$, Canada), and analyzed with OPENLAB imaging software (Improvision, Lexington, MA, USA). The images were exported to Adobe Photoshop, which was used to compensate for brightness, color and contrast.

\section{Nomenclature}

The nomenclature used in this study was agreed upon at the Avian Brain Nomenclature Forum (Reiner et al., 2004). The VTA was formerly known as the area ventralis of Tsai. Localization of injection sites in subdivisions of the hippocampal formation was based on the nomenclature of Atoji and Wild (2004): the parahippocampus of the atlas of Karten and Hodos (1967) corresponds to the dorsolateral, dorsomedial, cell-poor, magnocellular, and parvocellular regions of Atoji and Wild (2004); the hippocampus of Karten and Hodos (1967) corresponds the medial and lateral layers of the $\mathrm{V}$-shaped layer and the triangular region (see Fig. 1 of Atoji and Wild (2004)). In some cases, retrogradely labeled cells were found in the nBOR complex of the AOS. These neurons were classified according to their location in the nucleus of the basal optic root, proper (nBORp) or the nucleus of the basal optic root, pars dorsalis (nBORd), a band of cells running along the dorsal border of the nBORp (Brecha et al., 1980).

\section{RESULTS}

The results described below were acquired in one of four types of experiments: (i) immunohistochemistry experiments used to define the extent of the VTA; (ii) singlelabeling retrograde experiments utilizing either CTB, BDA, or fluorescent microspheres; (iii) double-labeling retrograde studies, using injections of fluorescent microspheres in the mclO and hippocampal formation of the same animal; and (iv) experiments combining fluorescent microspheres injected in the mclO or hippocampus with immunofluorohistochemistry for $\mathrm{TH}$-immunoreactivity.

\section{TH immunoreactivity: extent of the VTA in pigeons}

Areas with high concentrations of $\mathrm{TH}$-immunoreactive neurons and terminal fields define the VTA. In six birds processed for TH-reactivity, cell bodies, fiber fragments, and terminals were consistently labeled in the ventral tegmen- 


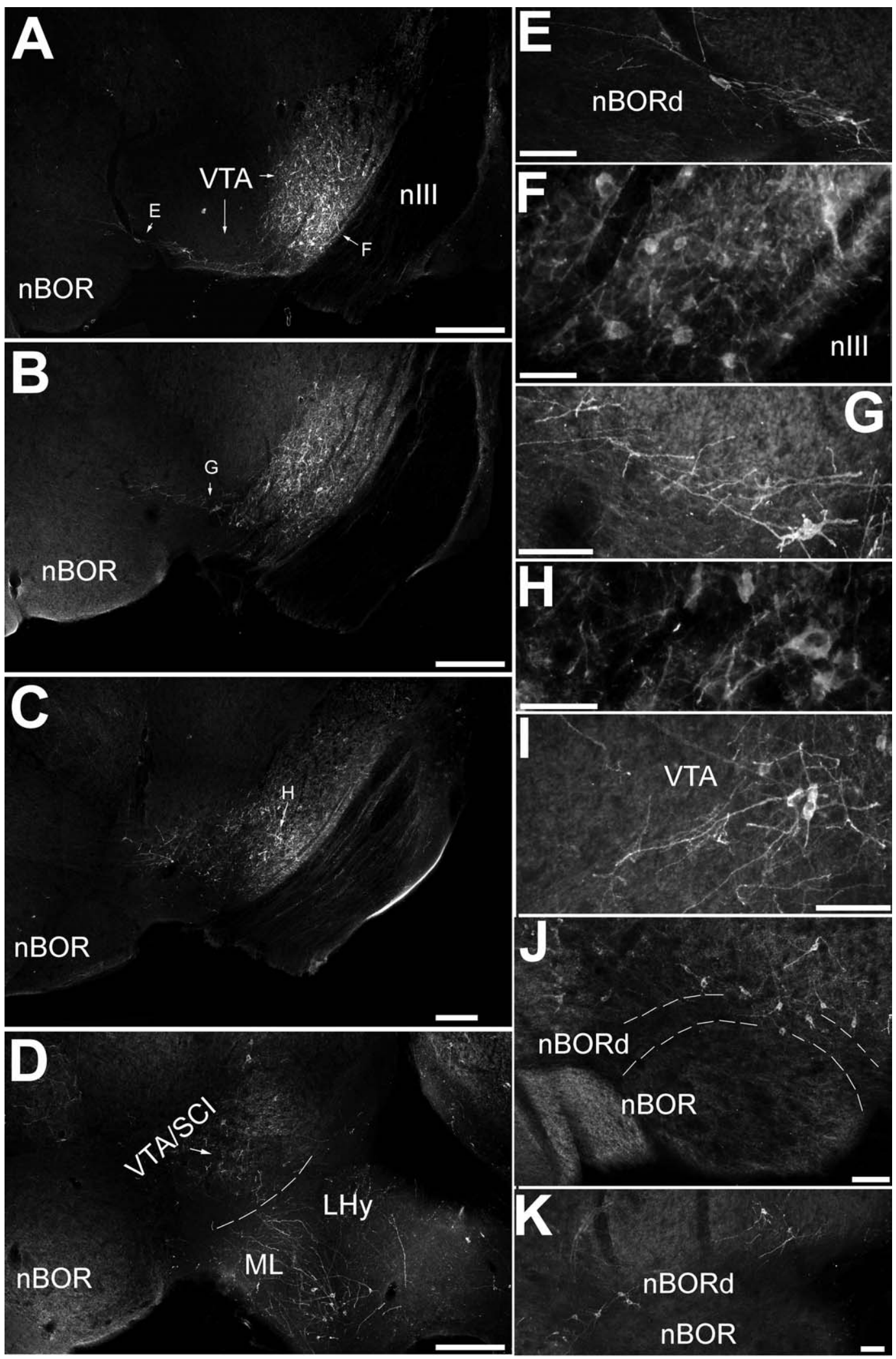

Fig. 2. Darkfield photomicrographs of TH-immunoreactive tissue in the VTA. In A-D, low magnification images of coronal sections spanning the VTA, each $160 \mu \mathrm{m}$ apart, showing the distribution of TH-positive areas in the VTA from case HFTH\#2 (A, most caudal; D, most rostral; midline to right of image). E-H show enlarged digital images of regions indicated in A, B, and C. F and $\mathrm{H}$ show terminals and cell bodies from the heart of the VTA. $G$ and I show cell bodies, fibers and terminals in the caudal VTA just medial and dorsal to the nBOR. $E$, $J$ and $K$ show images from three different cases illustrating TH-positive neurons located in and immediately adjacent to the caudal part of the nBORd. In all panels, lateral is to the left of the page, dorsal toward the top. LHy, lateral hypothalamic nucleus; ML, mamillaris lateralis; nIll, third cranial nerve; SCl, stratum cellulare internum. Scale bars $=500 \mu \mathrm{m} A-D$; $\mathrm{E}-\mathrm{K}, 50 \mu \mathrm{m}$. 
tum (as well as other known catecholaminergic areas of the brain, e.g. the locus coeruleus and substantia nigra). No labeling was observed in negative controls. In Fig. 2, darkfield photomicrographs of $\mathrm{TH}$-positive labeling throughout the VTA are shown. Fig. 2A-D is a series of coronal sections illustrating the TH-positive regions of the VTA from a representative case (HFTH2). The heaviest amount of labeling was found in the region adjacent to the third cranial nerve. This region was rich with labeled neurons and terminals (Fig. 2F, H, I). More rostrally, the labeling was not as dense (Fig. 2D). In all cases the TH-labeling extended laterally along the base of the brain toward the $\mathrm{nBOR}$, and a band of labeling extended across the dorsal edge of the $\mathrm{nBORd}$. This band contained both cell bodies and terminals, and was about 50-100 $\mu \mathrm{m}$ in width (see insets, Fig. 2A-C, E, G, J, K). Some of these terminals and cell bodies could clearly be ascribed to nBORd, especially in more caudal sections (e.g. Fig. 2J, K). Rostrally, the labeling in the VTA extended to the stratum cellulare internum and labeling was seen in the adjacent lateral hypothalamus (Fig. 2D). Thus, based on the distribution of $\mathrm{TH}$-immunoreactive elements, we were able to define the extent of the VTA in pigeons. VTA is a continuous reticular region, the bulk of which forms a column of TH-immunoreactive tissue adjacent to the third cranial nerve, medial to the $\mathrm{nBOR}$ and ventral to the red nucleus. A fine lateral extension of the VTA runs along the dorsal border of the $\mathrm{nBOR}$, through the ventral part of the mesencephalic reticular formation. VTA also includes dopaminergic regions immediately dorsal to the third cranial nerve, medial to the third cranial nerve and, in the more rostral sections, dorsal to the lateral hypothalamus and nucleus mamillaris lateralis.

The TH-positive labeling in the VTA was continuous with that in the substantia nigra pars compacta (A9) and the central gray and peri-rubral areas (A11). This is consistent with previous observations in birds and mammals (Lindvall and Björklund, 1983; Waldmann and Güntürkün, 1993; Gasbarri et al., 1997).

\section{Distribution of hippocampus-projecting and mclO-projecting neurons in the VTA}

The distribution of retrogradely labeled cells in the VTA was assessed in eight birds with a unilateral injection of retrograde tracer in the hippocampal formation and 11 birds with injections in the $\mathrm{mclO}$. Twelve of these cases involved an iontophoretic injection of low-salt CTB. In one case 3000 M.W. BDA was injected in the mclO, while six cases (flHF\#1, fllO\#1, HFTH\#1, HFTH\#2, IOTH\#1, IOTH\#2) used fluorescent latex microspheres as a retrograde tracer. The injections in the hippocampal formation were generally large, with considerable spread of the tracer across multiple subdivisions of the hippocampal formation, though the dorsolateral and dorsomedial subdivisions received the bulk of the injections. No significant difference in the distribution of retrogradely labeled cell bodies in the VTA was found between cases. Similarly, the distribution of labeled cells in the VTA did not differ significantly between mclO injections, and they will be considered together. (Rostral injections in mclO generally pro- duce more retrogradely labeled cells in the $\mathrm{nBOR}$ and VTA, but the distribution of these neurons does not differ from caudal injections in the mclO (Wylie, 2001)).

Fig. 3 shows camera lucida tracings illustrating the distribution of retrogradely labeled cells (black dots) in four representative cases. The projection from VTA to hippocampus is predominantly ipsilateral (Casini et al., 1986; Wylie et al., 1999a; Atoji and Wild, 2004) but the projection from the VTA and nBOR to the mclO is bilateral (Brecha et al., 1980; Wylie et al., 1997; Wylie, 2001). For mclO injections (Fig. 3A, B), ipsilateral labeling was concentrated in the caudal and ventral VTA, continuous with heavy labeling of the nBORd. Sparse-to-moderate labeling was found in more dorsal and rostral regions of the VTA. Moderate labeling of the contralateral VTA and nBOR complex, and moderate-to-heavy labeling of the rostral nBORp, was observed after mclO injections. This pattern of labeling is consistent with previous observations (Wylie, 2001). After hippocampal injections (3C, D), heavy labeling in the caudal sections was concentrated in the ventral VTA, and moderate labeling was observed in or adjacent to $\mathrm{nBORd}$. Heavy labeling continued through the rostral and dorsal VTA, including areas dorsal to the lateral hypothalamus and mamillaris lateralis, which were also densely labeled. While the distribution of retrogradely labeled cells did not differ significantly between injection sites in the hippocampus, those injections including the central and medial dorsomedial subdivision and other regions of the caudo-ventral hippocampus (the triangular subdivision and the $\mathrm{V}$-shaped layer) generally produced more retrograde labeling in VTA than injections more lateral in the dorsolateral subdivision or restricted to the dorsolateral subdivision, or injections in more rostral regions. In summary, injections in the mclO primarily labeled the nBORp, nBORd, and the caudo-ventral regions of the VTA medial to $\mathrm{nBOR}$, with significant labeling of the contralateral VTA, whereas injections in the hippocampus included heavy labeling of the caudal and ventral VTA but had a greater proportion of retrogradely labeled cells in the dorso-medial regions of the ipsilateral VTA, with sparse labeling of nBORd. The distributions are clearly overlapping, with the region of greatest overlap found in the caudal and ventral VTA.

\section{Morphology of hippocampus- and mclO-projecting VTA neurons}

Based on the Golgi-like staining of retrogradely labeled cells in VTA produced by CTB, we performed a coarse morphological assessment of neuron shape and size. (Note that this analysis was not intended to describe all possible cell types found in the VTA, nor do we claim that the morphological classes we describe form exclusive, distinct classes of neurons. Our purpose was to determine whether the mclO-projecting and hippocampus-projecting neurons had differing morphology, which would suggest that different populations of cells in the VTA project to the hippocampus vs. the mclO.) The results of our morphological analysis are shown in Table 1. A total of 225 neurons (101 from mclO injections, 124 from hippocampal injec- 
A

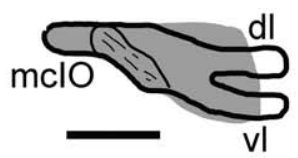

B
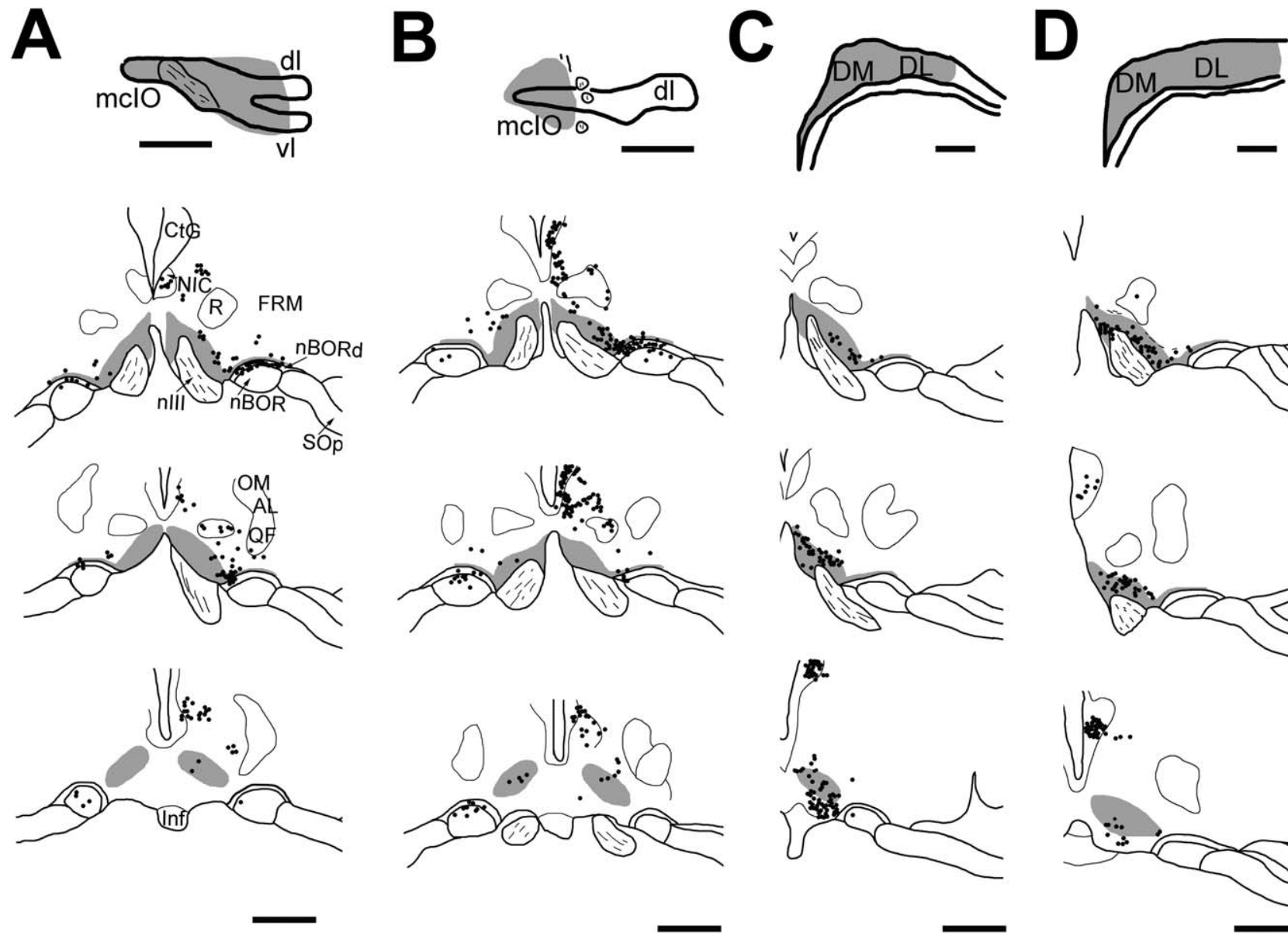
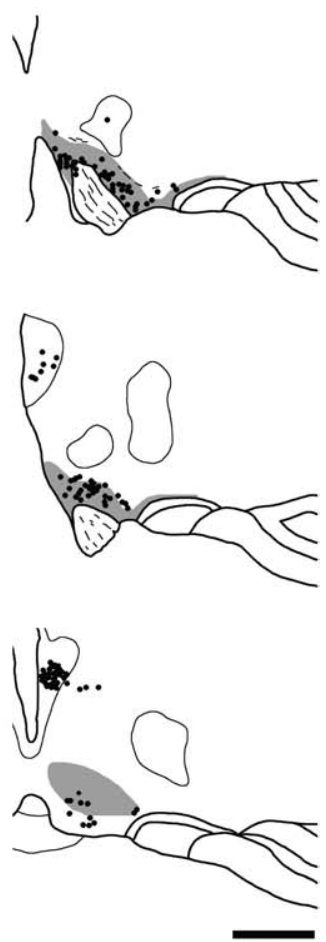

Fig. 3. Retrogradely labeled neurons in the VTA from injections in the mclO and hippocampal formation. Injection sites in the mclO (A, B) and hippocampus (C, D) are shown in the top row (gray areas) above three midbrain sections through the VTA (approximately $260 \mu \mathrm{m}$ apart, caudal (top) to rostral). The sections approximately match plates from A4.00 to A4.75 of Karten and Hodos (1967). Dots show the location of retrogradely labeled cells, and gray shading on the midbrain sections approximates the distributions of the VTA. AL, ansa lenticularis; CtG, central gray; DL, dorsolateral subdivision of the hippocampus; dl, dorsal lamella of the inferior olive; DM, dorsomedial subdivision of the hippocampus; FRM, mesencephalic reticular formation; NIC, interstitial nucleus of Cajal; nIII, third cranial nerve; QF, tractus quintofrontalis; QM, tractus occipitomesencephalicus; R, red nucleus; SOp, stratum opticum; vl, ventral lamella of the inferior olive. Scale bars $=400 \mu \mathrm{m}$ for injection sites in A-B; all other scale bars $=1 \mathrm{~mm}$.

tions), were classified as multipolar (the majority possessing three visible processes), fusiform (bipolar with ovoid soma), or round (with one to four visible processes). Length and width measurements were also recorded. As shown in Table 1, the morphological characteristics of the neurons projecting to the $\mathrm{mclO}$ and to the hippocampus were not distinguishable, and post hoc analysis of the lengths, widths, and areas using the Tukey's HSD method revealed no significant differences $(\alpha=.05)$ between the hippocampus-projecting and mclO-projecting VTA neurons.

Morphological measurements of $\mathrm{TH}$-positive neurons in the VTA are included in Table 1. While the general morphology of the $\mathrm{TH}$-positive neurons was comparable to the mclO- and hippocampus-projecting neurons, TH-positive cells were larger on average, reflecting the existence of a subset of very large TH-positive fusiform and multipolar neurons. Fusiform TH-positive neurons were also less common than in the retrogradely labeled samples. Post hoc analysis using Tukey's HSD revealed that TH-immu- noreactive multipolar neurons were significantly larger than multipolar neurons from $\mathrm{mclO}$ and hippocampal injections (mclO, length, $P<0.001$; width, $P<0.001$; area, $P<0.001$; hippocampus, length, $P<0.001$; area, $P<0.001$ ) and fusiform $\mathrm{TH}$-positive neurons were significantly greater than those from mclO injections (length, $P<0.041$; area, $P<0.003$ ) and hippocampal injections (length, $P<0.019$; area, $P<0.01)$.

\section{Retrograde fluorescent double labeling}

Four birds received injections of fluorescent retrograde tracer (red or green) in the hippocampal formation in conjunction with injection of an alternate color of tracer in the mclO. Retrogradely labeled cells from both injection sites were found throughout the VTA, and intermingled especially in the caudal VTA. Despite counting over 2200 retrogradely labeled neurons in the VTA, 941 of which were labeled from injections in the $\mathrm{mclO}$ and 1265 of which were labeled from hippocampal injections, no double-labeled 
Table 1. Morphological assessment of neurons in VTA projecting to the hippocampal formation and the $\mathrm{mclO}$

\begin{tabular}{lrrr}
\hline & Length \pm s.e.m. & Width \pm s.e.m. & \multicolumn{1}{c}{$\%$} \\
\hline Hippocampal formation & & & \\
$\quad$ Fusiform & $20.83 \pm 0.45$ & $8.71 \pm 0.23$ & 39.5 \\
$\quad$ Multipolar & $17.78 \pm 0.41$ & $9.36 \pm 0.20$ & 51.6 \\
$\quad$ Round & $12.59 \pm 0.73$ & $10.24 \pm 0.61$ & 8.9 \\
mclO & & & \\
$\quad$ Fusiform & $21.10 \pm 0.75$ & $8.00 \pm 0.25$ & 39.6 \\
$\quad$ Multipolar & $17.94 \pm 0.61$ & $8.76 \pm 0.26$ & 50.5 \\
$\quad$ Round & $11.37 \pm 0.60$ & $8.96 \pm 0.58$ & 9.9 \\
TH + ve & & & \\
$\quad$ Fusiform & $26.08 \pm 3.48$ & $9.34 \pm 0.51$ & 27.1 \\
$\quad$ Multipolar & $23.46 \pm 1.16$ & $12.34 \pm 0.67$ & 64.6 \\
$\quad$ Round & $13.20 \pm 1.09$ & $10.63 \pm 0.64$ & 8.3 \\
\hline
\end{tabular}

All length and width measurements are given in $\mu \mathrm{m}$. s.e.m., standard error of the mean.

neurons were found. That is, no individual neurons in VTA projected to both hippocampus and $\mathrm{mclO}$. Fig. 4A, B shows representative photomicrographs depicting mclOprojecting (red neurons) and hippocampus-projecting (green neurons) VTA neurons from these experiments. Digital images acquired under the FITC and rhodamine filters are shown in the left and middle panels, respectively, while the right panel is an overlay of the two. Fig. 4A shows a lower magnification shot through the VTA illustrating retrogradely labeled cells from $\mathrm{mclO}$ and hippocampal injections intermingled within the VTA. Fig. 4B shows a mclO-projecting neuron closely apposed to a hippocampus-projecting neuron. The locations of the digital images in $4 \mathrm{~A}$ and $4 \mathrm{~B}$ are superimposed on tracings of the corresponding coronal sections in the column to the right of the digital images. The cells depicted in $4 \mathrm{~B}$ were approximately $80 \mu \mathrm{m}$ rostral to those in $4 \mathrm{~A}$.

\section{TH-immunoreactivity of mclO- and hippocampus-projecting neurons in the VTA}

Four birds were used to determine if the hippocampusprojecting and/or the mclO-projecting VTA neurons are dopaminergic. Retrogradely labeled cell bodies in VTA from both hippocampal and mclO injections were located within and adjacent to the TH-positive areas. Double-labeled cells (i.e. cells labeled with green Lumafluor from an injection in hippocampus and Texas Red fluorescence from the TH secondary antibody) were observed in the VTA of the two birds (HFTH\#1, HFTH\#2) that received bilateral injections in the hippocampus. Cumulatively, across both of these animals, $8.2 \%$ of retrogradely labeled cell bodies $(n=487)$ were TH-positive. Representative double-labeled neurons from case HFTH\#1 are shown in Fig. 4C. Though these cells were located in the rostral and dorsomedial part of the VTA, double-labeled neurons were distributed throughout the VTA excepting the region bordering nBORd. In contrast, from the two cases with an injection in the $\mathrm{mclO}$, none of the retrogradely labeled neurons $(n=501)$ in the VTA or nBOR complex were THpositive, though their somas were often located among
TH-positive elements (e.g. Fig. 4D). Again, locations of the images in 4C and 4D are illustrated on the tracing in the far right column.

\section{DISCUSSION}

Our localization of $\mathrm{TH}$-immunoreactive elements in the pigeon VTA agrees with previous avian studies (Fuxe and Ljunggren, 1965; Ikeda and Gotoh, 1971; Dube and Parent, 1981; Bailhache and Balthazart, 1993; Waldmann and Güntürkün, 1993; Moons et al., 1994; Wynne and Güntürkün, 1995; Durstewitz et al., 1999). VTA is a continuous reticular region, the bulk of which forms a column of $\mathrm{TH}$-immunoreactive tissue adjacent to the third cranial nerve, medial to the $\mathrm{nBOR}$ and ventral to the red nucleus. There is a lateral extension from the VTA running along the dorsal border of nBOR. From our retrograde experiments we demonstrated that the distribution of VTA neurons that project to the hippocampus overlaps with that projecting to the mclO, particularly in the caudo-ventral VTA. Injections in the hippocampal formation incorporating the central and medial dorsomedial subdivision generate more retrograde labeling in the VTA than more dorso-lateral injections, consistent with Atoji and Wild (2004). Furthermore, VTA neurons projecting to the hippocampus and the $\mathrm{mclO}$ were morphologically indistinguishable (see Table 1). Finally, individual neurons do not project to both the hippocampal formation and $\mathrm{mclO}$, and a subset $(8.2 \%)$ of neurons projecting to the hippocampus, but not $\mathrm{mclO}$, is dopaminergic (i.e. $\mathrm{TH}$-immunoreactive).

\section{Comparison with studies on mammals}

Our findings agree with studies of the mesohippocampal projection in mammals. In rats, VTA provides dopaminergic and non-dopaminergic input to the limbic system, including the hippocampus (Fallon et al., 1984; Horel, 1988; Gasbarri et al., 1991, 1994a,b, 1997; Conde et al., 1995). Injections of anterograde neuronal tracers in the VTA of rats result in concentrated terminal field labeling in the ventral subiculum and adjacent CA1 field of the hippocampus, but less labeling in the dorsal hippocampus (Gasbarri et al., 1991, 1994a). VTA neurons projecting to the hippocampus are topographically organized: neurons projecting to the ventral hippocampus, primarily subiculum and adjacent CA1 field, are found in the ventral two-thirds of the VTA; neurons projecting to the dorsal subiculum and CA1 field are located in the ventral and dorsal borders of the VTA (Gasbarri et al., 1994b). Atoji and Wild (2004) postulated that dorsomedial subdivision of the avian hippocampus incorporates components comparable to Ammon's horn (CA1-4) and the subiculum, which suggests that neurons in VTA have homologous hippocampal targets in mammals and birds.

Wylie et al. (1999a) suggested that the hippocampusprojecting neurons in the dorsal border of the rat VTA, just ventral to the red nucleus, were located in the visual tegmental relay zone (VTRZ), a region of the ventral tegmentum containing neurons responsive to the optic flow (Giolli et al., 1985; Simpson et al., 1988b). The VTRZ appears 

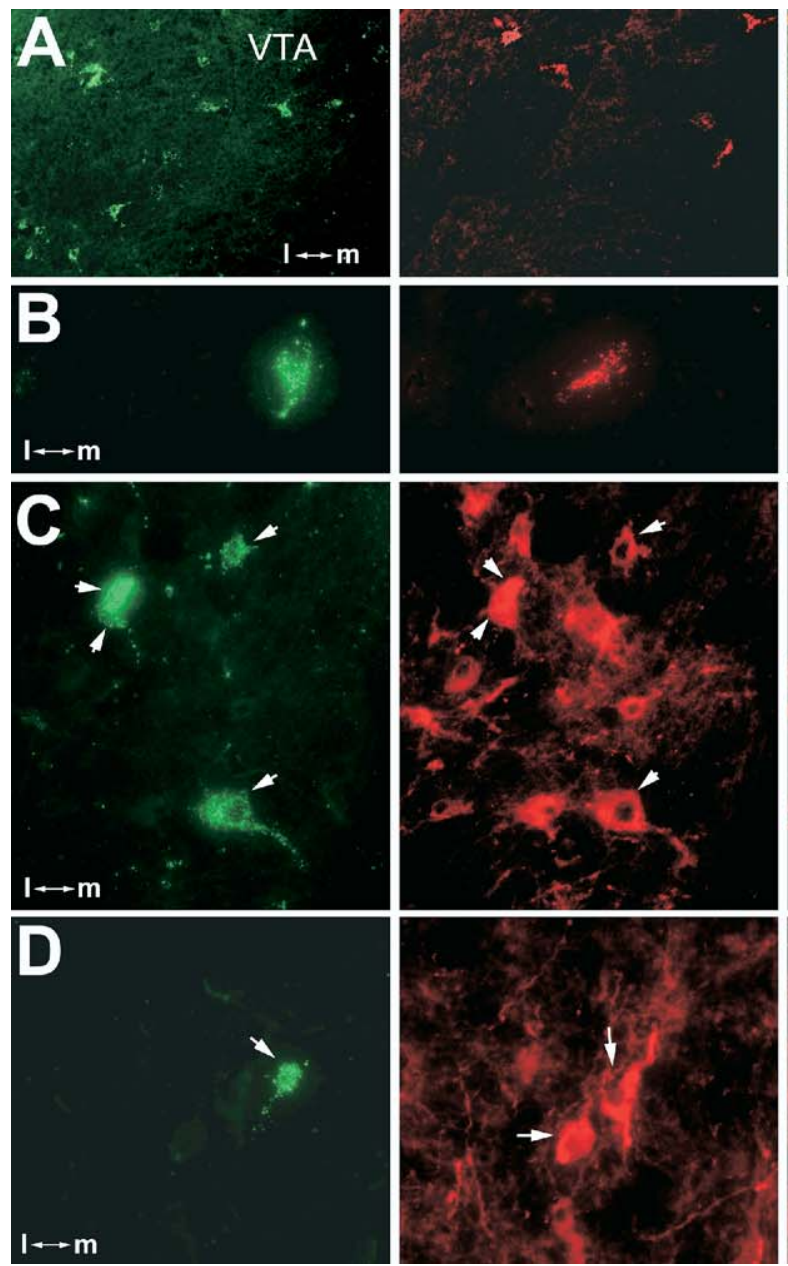
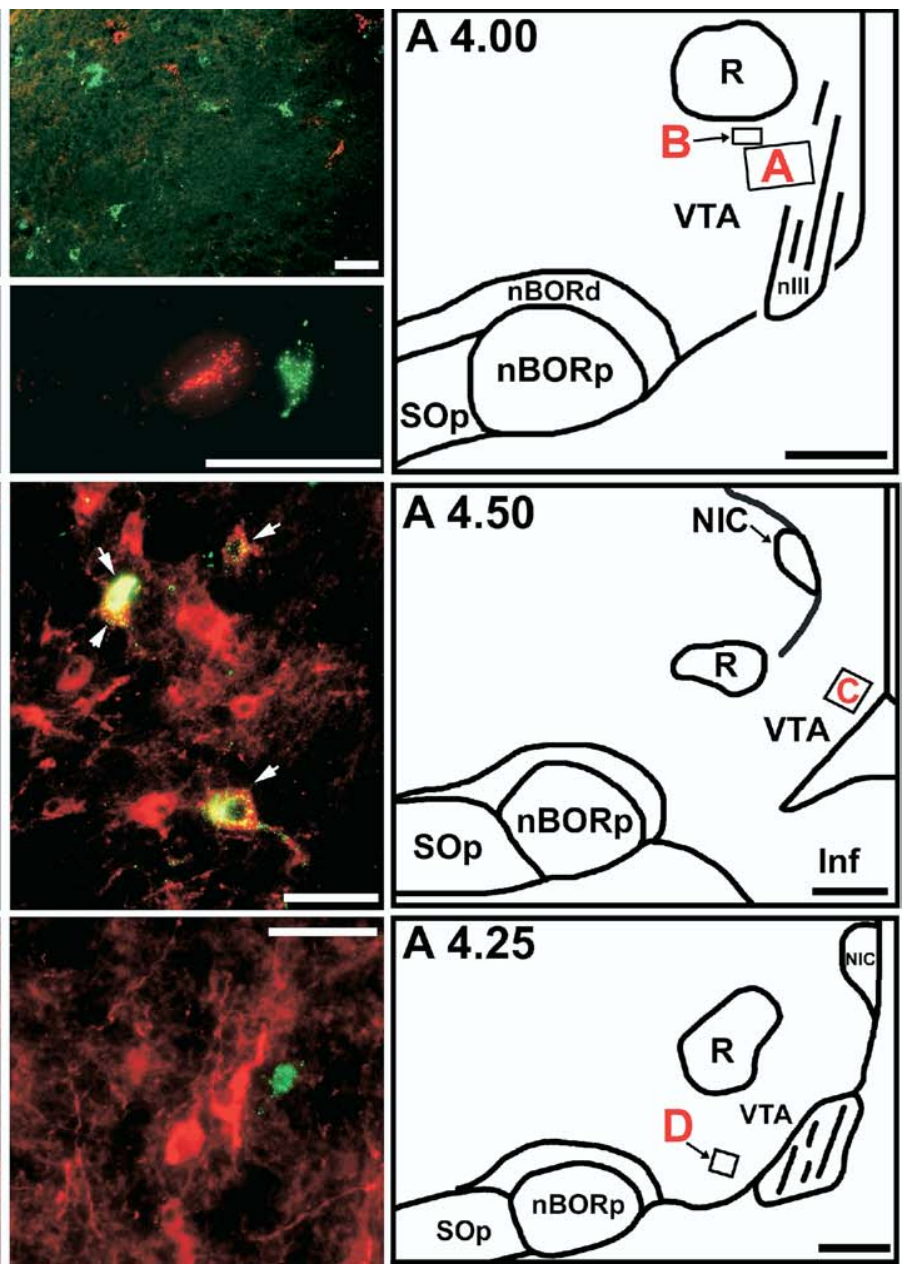

Fig. 4. Digital images showing fluorescent-labeled neurons in the VTA. For the digital images, the left column shows labeled cell bodies under the FITC filter, the middle panel shows labeled cells under the rhodamine (A-B) or Texas Red (C, D) filter, and the right panel is an overlay of the FITC and Texas Red/rhodamine images. Retrogradely labeled neurons shown in A-B were from injections of red Lumafluor latex microspheres in the mclO and green microspheres in the hippocampal formation. For all panels, left is lateral and dorsal is toward the top of the page. Tracings to the right of the digital images show the locations of the neurons within the corresponding coronal sections, with the rostral-caudal extent (mm anterior of interaural zero) annotated in the top left of the tracing. A shows retrogradely labeled neurons from injections in the mclO and hippocampus intermingled in the VTA lateral the third cranial nerve (nIII). In B, a green neuron from a hippocampal injection is closely juxtaposed a red neuron from an mclO injection in a section of the VTA $80 \mu \mathrm{m}$ rostral to the neurons in A. In C, the left panel shows four retrogradely labeled cells (white arrows) in the VTA from an injection in the hippocampus. Two of these neurons are overlapping. The middle panel shows TH-immunoreactive cells (labeled with a Texas Red-conjugated secondary antibody) in the same section, and the right panel shows an overlay, revealing that all four cells are double-labeled neurons. The left panel of D shows a retrogradely labeled neuron in the VTA from an injection in the mclO, the middle panel shows the TH-immunoreactivity in the same section, and the right panel shows the overlay. The neuron was not double-labeled, but was found immediately adjacent to TH-positive neurons (white arrows) in the heart of the VTA. I, lateral; m, medial; NIC, interstitial nucleus of Cajal; R, red nucleus; SOp, stratum opticum. Scale bars $=50 \mu \mathrm{m}$ in digital images; coronal tracings $500 \mu \mathrm{m}$.

equivalent to the optic flow sensitive regions of the VTA and the nBORd in pigeons (Giolli et al., 1985; Simpson et al., 1988a,b). As in pigeons, the VTA neurons projecting to the inferior olive in rats are not dopaminergic, but are intermixed in the VTA with dopaminergic and non-dopaminergic neurons projecting to the telencephalon (Fallon et al., 1984). As such, VTRZ offers a mammalian equivalent of the hippocampus-projecting neurons in the pigeon VTA.

The lack of double-labeled neurons in pigeon VTA from retrograde tracers injected in the $\mathrm{mclO}$ and the hippocampus is also consistent with mammalian studies, given that a lack of collateralization is a general characteristic of VTA efferents in rats (Takada and Hattori, 1987; Gasbarri et al.,
1997). Finally, the low percentage of TH-positive neurons projecting to the hippocampal formation in our study $(8.2 \%)$ agrees with previous studies in rats (10-18\%; Gasbarri et al., 1994b, 1997).

\section{Role of optic flow in spatial memory and path integration}

Although it is well established that the projection from the VTA to the $\mathrm{mclO}$ is involved in the optokinetic response and the analysis of optic flow, the assertion that the VTA projection to the hippocampus is involved in the analysis of optic flow is more tenuous. The avian hippocampal forma- 
tion is considered an homologue of the mammalian hippocampus based on developmental (Källen, 1962; Redies et al., 2001), cytoarchitectural (Montagnese et al., 1996; Tömböl et al., 2000a,b), neurochemical (Erichsen et al., 1991; Krebs et al., 1991; Székely and Krebs, 1996), neural connectivity (Casini et al., 1986; Székely and Krebs, 1996; Wylie et al., 1999a; Atoji et al., 2002; Kahn et al., 2003; Atoji and Wild, 2004), and physiological grounds (Siegel et al., 2000, 2005). Furthermore, behavioral studies suggest that the avian hippocampus functions in spatial cognition in a manner similar to the mammalian hippocampus (Bingman et al., 1990; Bingman and Yates, 1992; Fremouw et al., 1997; Colombo et al., 1997; Gagliardo et al., 2002; for review see Sherry et al., 1992; Colombo and Broadbent, 2000; Macphail, 2002). The initial studies in mammals implicating the hippocampal formation in path integration suggested that ideothetic information from self-motion originates in the vestibular system (McNaughton et al., 1995, 1996; Muller et al., 1996). Wylie et al. (1999a) proposed an additional ideothetic cue, namely optic flow. This proposal is supported by studies indicating that both vestibular and visual motion cues influence head-direction cells and hippocampal place cells and may thus be used for path integration (Blair and Sharp, 1996; Terrazas et al., 2005). Wylie et al. (1999a) demonstrated that the VTA of pigeons receives input from structures dedicated to the analysis of optic flow, namely nBOR and LM, and that a subset of neurons in the VTA of pigeons responds to precise patterns of optic flow generated by self-rotation or self-translation. Combined with the work of Wylie et al. (1999a), the morphological and topographical similarities between hippocampus-projecting and mclO-projecting neurons in the VTA suggest these neurons may relay information related to the analysis of optic flow to both structures. However, it is possible that in a reticular area such as VTA cohabitant subpopulations of neurons may have distinct afferents, efferents, and functions (Fallon et al., 1984).

\section{The dopaminergic mesohippocampal pathway}

While the functional significance of the dopaminergic mesohippocampal projection is unclear, a role in mediating locomotor activity and spatial memory has been suggested (Gasbarri et al., 1997) based on studies of the effects of stimulation using dopamine agonists and lesions of dopaminergic neurons in the VTA and hippocampus of rats. These studies indicate that injections of dopamine agonists in the hippocampus increase spontaneous and exploratory behavior (Smialowski, 1976), while lesions of the dopaminergic neurons in VTA reduces spontaneous locomotor activity (Kelly and Iversen, 1976; Koob et al., 1981). Further, catecholamine agonists injected into the dorsal hippocampus enhance performance in a win-shift radial maze task (Packard and White, 1991) and bilateral lesions of dopaminergic neurons in the dorsal and ventral subiculum and CA1 field impair performance in the hippocampal dependent spatial water maze task (Gasbarri et al., 1996). Little work, in either mammals or birds, has examined the function of the non-dopaminergic input to the hippocam- pus. Given that this accounts for $80-90 \%$ of the VTAderived projection upon the hippocampus, the role of this projection in hippocampal dependent memory processes remains a significant question and an avenue for future study.

Acknowledgments-Supporting Grants: This research was supported by funding from the Natural Sciences and Engineering Research Council of Canada and Canadian Institute for Health Research (NSERC, CIHR; to D.R.W.-W.) D.R.W.-W. was supported by the Canada Research Chairs Program. K.G.T. was supported by CIHR, the Heart and Stroke Foundation of Canada, and the Davey Fund for Brain Research. I.R.W. and J.M.P.P. were supported by fellowships from NSERC and the Alberta Heritage Foundation for Medical Research.

\section{REFERENCES}

Arends JJA, Voogd J (1989) Topographic aspects of the olivocerebellar system in the pigeon. Exp Brain Res Suppl 17:52-57.

Atoji Y, Wild JM, Yamamoto Y, Suzuki Y (2002) Intratelencephalic connections of the hippocampus in pigeons (Columba livia). J Comp Neurol 447:177-199.

Atoji Y, Wild JM (2004) Fiber connections of the hippocampal formation and septum and subdivisions of the hippocampal formation in the pigeon as revealed by tract tracing and kainic acid lesions. J Comp Neurol 475:426-461.

Bailhache T, Balthazart J (1993) The catecholaminergic system of the quail brain: immunocytochemical studies of dopamine betahydroxylase and tyrosine hydroxylase. J Comp Neurol 329: 230-256.

Bingman VP, loale P, Casini G, Bagnoli P (1990) The avian hippocampus: evidence for a role in the development of the homing pigeon navigational map. Behav Neurosci 104:906-911.

Bingman VP, Yates G (1992) Hippocampal lesions impair navigational learning in experienced homing pigeons. Behav Neurosci 106: 229-232.

Blair HT, Sharp PE (1996) Visual and vestibular influences on headdirection cells in the anterior thalamus of the rat. Behav Neurosci 110:643-660.

Brecha N, Karten HJ, Hunt SP (1980) Projections of the nucleus of the basal optic root in the pigeon: an autoradiographic and horseradish peroxidase study. J Comp Neurol 189:615-670.

Casini G, Bingman VP, Bagnoli P (1986) Connections of the pigeon dorsomedial forebrain studied with WGA-HRP and $3 \mathrm{H}$-proline. J Comp Neurol 245:454-470.

Clarke PG (1977) Some visual and other connections to the cerebellum of the pigeon. J Comp Neurol 174:535-552.

Colombo M, Broadbent N (2000) Is the avian hippocampus a functional homologue of the mammalian hippocampus? Neurosci Biobehav Rev 24:465-484.

Colombo M, Cawley S, Broadbent N (1997) The effects of hippocampal and area parahippocampalis lesions in pigeons: II. Concurrent discrimination and spatial memory. Q J Exp Psychol B 50:172-189.

Conde F, Maire-Lepoivre E, Audinat E, Crepel F (1995) Afferent connections of the medial frontal cortex of the rat. II. Cortical and subcortical afferents. J Comp Neurol 352:567-593.

Crowder NA, Winship IR, Wylie DRW (2000) Topographic organization of inferior olive cells projecting to translational zones in the vestibulocerebellum of pigeons. J Comp Neurol 419:87-95.

Darwin C (1873) On the origin of certain instincts. Nature 7:417-418.

Dube L, Parent A (1981) The monoamine-containing neurons in avian brain: I. A study of the brain stem of the chicken (Gallus domesticus) by means of fluorescence and acetylcholinesterase histochemistry. J Comp Neurol 196:695-708.

Durstewitz D, Kroner S, Güntürkün O (1999) The dopaminergic innervation of the avian telencephalon. Prog Neurobiol 59:161-195. 
Erichsen JT, Bingman VP, Krebs JR (1991) The distribution of neuropeptides in the dorsomedial telencephalon of the pigeon (Columba livia): a basis for regional subdivisions. J Comp Neurol 314:478-492.

Fallon JH, Schmued LC, Wang C, Miller R, Banales G (1984) Neurons in the ventral tegmentum have separate populations projecting to telencephalon and inferior olive, are histochemically different, and may receive direct visual input. Brain Res 321:332-336.

Fite KV, Brecha N, Karten HJ, Hunt SP (1981) Displaced ganglion cells and the accessory optic system of the pigeon. J Comp Neurol 195:279-288.

Foster TC, Castro CA, McNaughton BL (1989) Spatial selectivity of rat hippocampal neurons: dependence on preparedness for movement. Science 244:1580-1582.

Fremouw T, Jackson-Smith P, Kesner RP (1997) Impaired place learning and unimpaired cue learning in hippocampal-lesioned pigeons. Behav Neurosci 111:963-975.

Fuxe K, Ljunggren $L$ (1965) Cellular localization of monoamines in the upper brain stem of the pigeon. J Comp Neurol 125:355-381.

Gagliardo A, Odetti F, loale P, Bingman VP, Tuttle S, Vallortigara G (2002) Bilateral participation of the hippocampus in familiar landmark navigation by homing pigeons. Behav Brain Res 136: 201-209.

Gamlin PDR, Cohen DH (1988a) The retinal projections to the pretectum in the pigeon (Columba livia). J Comp Neurol 269:1-17.

Gamlin PDR, Cohen DH (1988b) Projections of the retinorecipient pretectal nuclei in the pigeon (Columba livia). J Comp Neurol 269:18-46.

Gasbarri A, Campana E, Pacitti C, Hajdu F, Tombol T (1991) Organization of the projections from the ventral tegmental area of Tsai to the hippocampal formation in the rat. J Hirnforsch 32:429-437.

Gasbarri A, Packard MG, Campana E, Pacitti C (1994a) Anterograde and retrograde tracing of projections from the ventral tegmental area to the hippocampal formation in the rat. Brain Res Bull 33:445-452.

Gasbarri A, Verney C, Innocenzi R, Campana E, Pacitti C (1994b) Mesolimbic dopaminergic neurons innervating the hippocampal formation in the rat: a combined retrograde tracing and immunohistochemical study. Brain Res 668:71-79.

Gasbarri A, Sulli A, Innocenzi R, Pacitti C, Brioni JD (1996) Spatial memory impairment induced by lesion of the mesohippocampal dopaminergic system in the rat. Neuroscience 74:1037-1044.

Gasbarri A, Sulli A, Packard MG (1997) The dopaminergic mesencephalic projections to the hippocampal formation in the rat. Prog Neuropsychopharmacol Biol Psychiatry 21:1-22.

Gibson JJ (1954) The visual perception of objective motion and subjective movement. Psychol Rev 61:304-314.

Giolli RA, Blanks RHI, Torigoe Y, Williams DD (1985) Projections of the medial terminal accessory optic nucleus, ventral tegmental nuclei, and substantia nigra of rabbit and rat as studied by retrograde axonal transport of horseradish peroxidase. J Comp Neurol 232:99-116

Horel JA (1988) Limbic neocortical interrelations. In: Neurosciences, Vol. 4: Comparative primate biology (Steklis HD, Erwin J, eds), pp 81-97. New York: Wiley-Liss.

Ikeda H, Gotoh J (1971) Distribution of monoamine-containing cells in the central nervous system of the chicken. Jpn J Pharmacol 21: 763-784.

Kahn MC, Hough GE 2nd, Ten Eyck GR, Bingman VP (2003) Internal connectivity of the homing pigeon (Columba livia) hippocampal formation: an anterograde and retrograde tracer study. J Comp Neurol 459:127-141.

Källen BI (1962) Embryogenesis of brain nuclei in the chick telencephalon. Ergeb Anat Entwicklungsgesch 36:62-82.

Karten HJ, Hodos W (1967) A stereotaxic atlas of the brain of the pigeon (Columba livia). Baltimore: Johns Hopkins Press.
Karten HJ, Fite KV, Brecha N (1977) Specific projection of displaced retinal ganglion cells upon the accessory optic system in the pigeon (Columba livia). Proc Natl Acad Sci U S A 74:1752-1756.

Kelly PH, Iversen SD (1976) Selective 6OHDA-induced destruction of mesolimbic dopamine neurons: abolition of psychostimulant-induced locomotor activity in rats. Eur J Pharmacol 40:45-56.

Kiss JZ, Péczely P (1987) Distribution of tyrosine-hydroxylase (TH)immunoreactive neurons in the diencephalon of the pigeon (Columba livia domestica). J Comp Neurol 257:333-346.

Koob GF, Stinus L, Le Moal M (1981) Hyperactivity and hypoactivity produced by lesions to the mesolimbic dopamine system. Behav Brain Res 3:341-359.

Krebs JR, Erichsen JT, Bingman VP (1991) The distribution of neurotransmitters and neurotransmitter-related enzymes in the dorsomedial telencephalon of the pigeon (Columba livia). J Comp Neurol 314:467-477.

Lau KL, Glover RG, Linkenhoker B, Wylie DR (1998) Topographical organization of inferior olive cells projecting to translation and rotation zones in the vestibulocerebellum of pigeons. Neuroscience 85: 605-614.

Lindvall O, Björklund A (1983) Dopamine and norepinephrine containing neuron systems: Their anatomy in the rat brain. In: Chemical neuroanatomy (Emison PC, ed), pp 229-255. New York: Raven Press.

Macphail EM (2002) The role of avian hippocampus in spatial memory. Psychologica 23:93-108.

McNaughton BL, Barnes CA, Gerrard JL, Gothard K, Jung MW, Knierim JJ, Kudrimoti H, Qin Y, Skaggs WE, Suster M, Weaver KL (1996) Deciphering the hippocampal polyglot: the hippocampus as a path integration system. J Exp Biol 199:173-185.

McNaughton BL, Knierim JJ, Wilson MA (1995) Vector encoding and the vestibular foundations of spatial cognition: neurophysiological and computational mechanisms. In: The cognitive neurosciences (Gazzaniga MS, ed), pp 585-595. Cambridge, MA: MIT.

Montagnese CM, Krebs JR, Meyer G (1996) The dorsomedial and dorsolateral forebrain of the zebra finch, Taeniopygia guttata: a Golgi study. Cell Tissue Res 283:263-282.

Moons L, van Gils J, Ghijsels E, Vandesande F (1994) Immunocytochemical localization of L-dopa and dopamine in the brain of the chicken (Gallus domesticus). J Comp Neurol 346:97-118.

Muller RU, Ranck JB, Jr, Taube JS (1996) Head direction cells: properties and functional significance. Curr Opin Neurobiol 6:196-206.

Oades RD, Halliday GM (1987) Ventral tegmental (A10) system: 1. Anatomy and connectivity. Brain Res 434:117-165.

Packard MG, White NM (1991) Dissociation of hippocampus and caudate nucleus memory systems by posttraining intracerebral injection of dopamine agonists. Behav Neurosci 105:295-306.

Pakan JM, Todd KG, Nguyen AP, Winship IR, Hurd PL, Jantzie LL, Wylie DR (2005) Inferior olivary neurons innervate multiple zones of the flocculus in pigeons (Columba livia). J Comp Neurol 486: $159-168$.

Redies C, Medina L, Puelles L (2001) Cadherin expression by embryonic divisions and derived gray matter structures in the telencephalon of the chicken. J Comp Neurol 438:253-285.

Reiner A, Perkel DJ, Bruce LL, Butler AB, Csillag A, Kuenzel W, Medina L, Paxinos G, Shimizu T, Striedter G, Wild M, Ball GF, Durand S, Güntürkün O, Lee DW, Mello CV, Powers A, White SA, Hough G, Kubikova L, Smulders TV, Wada K, Dugas-Ford J, Husband S, Yamamoto K, Yu J, Siang C, Jarvis ED, Avian Brain Nomenclature Forum (2004) Revised nomenclature for avian telencephalon and some related brainstem nuclei. J Comp Neurol 473:377-414. Erratum in: J Comp Neurol 475:288.

Reiner A, Brecha N, Karten HJ (1979) A specific projection of retinal displaced ganglion cells to the nucleus of the basal optic root in the chicken. Neuroscience 4:1679-1688.

Sherry DF, Jacobs LF, Gaulin SJ (1992) Spatial memory and adaptive specialization of the hippocampus. Trends Neurosci 15:298-303. 
Siegel JJ, Nitz D, Bingman VP (2000) Hippocampal theta rhythm in awake, freely moving homing pigeons. Hippocampus 10:627-631.

Siegel JJ, Nitz D, Bingman VP (2005) Spatial-specificity of single-units in the hippocampal formation of freely moving homing pigeons. Hippocampus 15:26-40.

Simpson Jl (1984) The accessory optic system. Annu Rev Neurosci 7:13-41.

Simpson JI, Leonard CS, Soodak RE (1988a) The accessory optic system of rabbit. II. Spatial organization of direction selectivity. J Neurophysiol 60:2055-2072.

Simpson JI, Leonard CS, Soodak RE (1988b) The accessory optic system. Analyzer of self-motion. Ann N Y Acad Sci 545:170-179.

Smialowski A (1976) The effect of intrahippocampal administration of dopamine or apomorphine on EEG of limbic structures in the rabbit brain. Pol J Pharmacol Pharm 28:579-585.

Székely AD, Krebs JR (1996) Efferent connectivity of the hippocampal formation of the zebra finch (Taenopygia guttata): an anterograde pathway tracing study using Phaseolus vulgaris leucoagglutinin. J Comp Neurol 368:198-214.

Takada M, Hattori T (1987) Organization of ventral tegmental area cells projecting to the occipital cortex and forebrain in the rat. Brain Res 418:27-33.

Terrazas A, Krause M, Lipa P, Gothard KM, Barnes CA, McNaughton BL (2005) Self-motion and the hippocampal spatial metric. J Neurosci 25:8085-8096.

Tömböl T, Davies DC, Nemeth A, Alpar A, Sebesteny T (2000a) A Golgi and a combined Golgi/GABA immunogold study of local circuit neurons in the homing pigeon hippocampus. Anat Embryol (Berl) 201:181-196.

Tömböl T, Davies DC, Nemeth A, Sebesteny T, Alpar A (2000b) A comparative Golgi study of chicken (Gallus domesticus) and homing pigeon (Columba livia) hippocampus. Anat Embryol (Berl) 201:85-101.

Veenman CL, Reiner A, Honig MG (1992) Biotinylated dextran amine as an anterograde tracer for single- and double-labeling studies. J Neurosci Methods 41:239-254.

Waespe W, Henn V (1987) Gaze stabilization in the primate. The interaction of the vestibulo-ocular reflex, optokinetic nystagmus, and smooth pursuit. Rev Physiol Biochem Pharmacol 106: 37-125.

Waldmann C, Güntürkün O (1993) The dopaminergic innervation of the pigeon caudolateral forebrain: immunocytochemical evidence for a "prefrontal cortex" in birds? Brain Res 600:225-234.
Whishaw IQ, Maaswinkel H (1998) Rats with fimbria-fornix lesions are impaired in path integration: a role for the hippocampus in "sense of direction." J Neurosci 18:3050-3058.

Whishaw IQ, McKenna JE, Maaswinkel H (1997) Hippocampal lesions and path integration. Curr Opin Neurobiol 7:228-234.

Wild JM (1993) Descending projections of the songbird nucleus robustus archistrialis. J Comp Neurol 338:225-241.

Wilson MA, McNaughton BL (1993) Dynamics of the hippocampal ensemble code for space. Science 261:1055-1058.

Winship IR, Wylie DR (2001) Responses of neurons in the medial column of the inferior olive in pigeons to translational and rotational optic flowfields. Exp Brain Res 141:63-78.

Wise RA (2004) Dopamine, learning and motivation. Nat Rev Neurosci 5:1-12.

Wylie DRW (2001) Projections from the nucleus of the basal optic root and nucleus lentiformis mesencephali to the inferior olive in pigeons (Columba livia). J Comp Neurol 429:502-513.

Wylie DR, Brown MR, Barkley RR, Winship IR, Crowder NA, Todd KG (2003a) Zonal organization of the vestibulocerebellum in pigeons (Columba livia): II. Projections of the rotation zones of the flocculus. J Comp Neurol 456:140-153.

Wylie DR, Brown MR, Winship IR, Crowder NA, Todd KG (2003b) Zonal organization of the vestibulocerebellum in pigeons (Columba livia): III. Projections of the translation zones of the ventral uvula and nodulus. J Comp Neurol 465:179-194.

Wylie DR, Glover RG, Aitchison JD (1999a) Optic flow input to the hippocampal formation from the accessory optic system. J Neurosci 19:5514-5527.

Wylie DRW, Winship IR, Glover RG (1999b) Projections from the medial column of the inferior olive to different classes of rotationsensitive Purkinje cells in the flocculus of pigeons. Neurosci Lett 268:97-100.

Wylie DR, Linkenhoker B, Lau KL (1997) Projections of the nucleus of the basal optic root in pigeons (Columba livia) revealed with biotinylated dextran amine. J Comp Neurol 384:517-536.

Wylie DR, Ogilvie CJ, Crowder NA, Barkley RR, Winship IR (2005) Telencephalic projections to the nucleus of the basal optic root and pretectal nucleus lentiformis mesencephali in pigeons. Vis Neurosci 22:237-247.

Wynne B, Güntürkün O (1995) Dopaminergic innervation of the telencephalon of the pigeon (Columba livia): a study with antibodies against tyrosine hydroxylase and dopamine. J Comp Neurol 357:446-464. 